\title{
Health-related quality of life of patients with squamous cell carcinoma: a comparison according to tumor location
}

Paula Mariano de Oliveira IRIYA(a) Luiz Wanderlei ROMANISZEN(b) Thais Maria Freire FERNANDES(a) Marcelo Lupion POLETI(c)

(a) Universidade Norte do

Paraná - Unopar, Londrina, PR, Brazil.

(b)Hospital do Câncer de Londrina, Department of Head and Neck Surgery, Londrina, PR, Brazil.

(c) Instituto Federal do Paraná, Londrina, PR, Brazil.
Abstract: The aim of this study was to evaluate the health-related quality of life (QOL) of patients with squamous cell carcinoma (SCC) according to tumor location. The sample consisted of 27 patients with primary SCC in the oral cavity $(n=15)$, pharynx $(n=7)$, and larynx $(n=5)$ who were undergoing cancer treatment at the Cancer Hospital of Londrina, regardless of age, sex, clinical stage, and type of antineoplastic treatment. Health-related QOL was evaluated using the 30-item CancerQuality of Life Questionnaire (QLQ-C30), the 35-item Head and Neck Cancer-Quality of Life Questionnaire (QLQ-HN35), and the University of Washington Quality of Life Questionnaire (UW-QOL). These questionnaires were administered individually to each patient before ambulatory care. Sociodemographic data (age and sex) and clinical data ( $\mathrm{T}$ stage, tumor location, and type of antineoplastic treatment) were collected from the patients' medical records. Scores were compared according to tumor location using the chi-squared test and one-way analysis of variance $(p<0.05)$. No score differed significantly according to tumor location. It can be concluded that the health-related QOL of patients with SCC was not influenced by tumor location.

Keywords: Quality of Life; Carcinoma, Squamous Cell; Neoplasms.

\section{Introduction}

that they have no commercial or associative interest that represents a conflict of interest in connection with the manuscript.

Corresponding Author:

Marcelo Lupion Poleti

E-mail: marcelo_poleti@yahoo.com.br

htrps://doi.org/10.1590/1807-3107BOR-2017.vol31.0105

Submitted: June 28, 2017

Accepted for publication: Oct 25, 2017

Last revision: Nov 10, 2017
The World Health Organization defined quality of life (QOL) as being relative to an individual's perception of their position in life, the cultural context, and the individual's goals, expectations, parameters, and social relations. ${ }^{1} \mathrm{QOL}$ is a multidimensional abstract construct that may be based on individual or collective assessment, and may be evaluated generically or specifically by various instruments and questionnaires. ${ }^{2,3,4,5,6,7}$ Generic questionnaires do not evaluate a specific disease; specific questionnaires are used to evaluate groups of patients with a certain type of disease in common. ${ }^{3,8}$ Head and neck cancer is among the diseases that can affect health-related QOL profoundly. 4,5,9,10,11,12

Most tools available for evaluation of QOL in head and neck cancer patients were developed originally in English, ${ }^{13}$ and must be translated and validated for use in populations that speak other languages. The instruments used most commonly to assess health-related QOL in head and neck cancer are the 30-item Cancer-Quality of Life Questionnaire (QLQ-C30) and 
the 35-item Head and Neck Cancer-Quality of Life Questionnaire module (QLQ-HN35), developed by the European Organisation for Research and Treatment of Cancer (EORTC), and the University of Washington Quality of Life Questionnaire (UW-QOL). ${ }^{2,3,4,6,8}$ The QLQ-C30 and QLQ-HN35 are instruments composed of questions that assess the patient's QOL in the last week with total score ranges of $0-100 \mathrm{~L}$. ${ }^{3,14}$ The QLQ-C30, which is the EORTC's core QOL instrument, includes a single general health/QOL scale, five functional scales, eight physical symptom scales, and a single item related to financial difficulty (see Table 1 for scales). The QLQ-HN35 is the EORTC's head and neck cancer-specific module questionnaire (EORTC modules are each administered with the core QLQ-C30 assessment). It includes 7 multi-item scales and 11 single-item scales (see Table 2 for scales). The UW-QOL questionnaire is structured as a 12-item (see Table 3 for items). ${ }^{5,8}$ Each item is scored on a $0-100$ scale.,14

Given the small number of QOL studies in patients with head and neck cancer, an expansion of knowledge about QOL assessment in patients undergoing cancer treatment is needed..$^{15}$ Therefore, the aim of this study was to evaluate the health-related QOL of patients with squamous cell carcinoma (SCC) according to tumor location.

\section{Methodology}

This study was quantitative, observational, and cross-sectional. The sample consisted of 27 patients with primary SCC in the oral cavity $(n=15)$, pharynx $(n=7)$, and larynx $(n=5)$ who were undergoing treatment at the Cancer Hospital of Londrina. Inclusion did not depend on patients' age, sex, clinical stage, or type of antineoplastic treatment. Patients with recurrent disease were not included. The Ethics Committee of the University of North Paraná approved this study (protocol no. 846,397). All patients provided written information consent to participate in this study.

Patients' health-related QOL was evaluated individually using the QLQ-C30 (version 3.0), the QLQ-HN35 module, and the UW-QOL (version 4) prior to outpatient care. The UW-QOL domain-importance question, in which patients are asked to identify which 3 of the 12 domains have been the most important to their QOL in the last 7 days, was applied in addition to the 12 main domain items. After questionnaire application, sociodemographic (age and sex) and clinical (diagnostic, tumor location, clinical stage, type of antineoplastic treatment) data were collected from the patients' medical records. Questionnaire

Table 1. QLQ-C30 scores according to tumor location.

\begin{tabular}{|c|c|c|c|c|c|c|c|}
\hline \multirow{3}{*}{ Scale/item } & \multicolumn{6}{|c|}{ SCC location } & \multirow{3}{*}{$P$} \\
\hline & \multicolumn{2}{|c|}{ Oral $(n=15)$} & \multicolumn{2}{|c|}{ Pharyngeal $(n=7)$} & \multicolumn{2}{|c|}{ Laryngeal $(n=5)$} & \\
\hline & Mean & SE & Mean & SE & Mean & SE & \\
\hline \multicolumn{8}{|l|}{ Functional scales } \\
\hline Physical & 74 & 5 & 66 & 12 & 65 & 12 & 0.760 \\
\hline Role & 78 & 5 & 50 & 11 & 63 & 13 & 0.063 \\
\hline Emotional & 69 & 6 & 50 & 14 & 52 & 16 & 0.418 \\
\hline Cognitive & 28 & 9 & 24 & 11 & 60 & 14 & 0.186 \\
\hline Social & 82 & 6 & 62 & 14 & 80 & 11 & 0.277 \\
\hline \multicolumn{8}{|l|}{ Physical symptoms } \\
\hline Fatigue & 42 & 7 & 56 & 7 & 38 & 8 & 0.432 \\
\hline Nausea and vomiting & 19 & 8 & 43 & 13 & 10 & 6 & 0.164 \\
\hline Pain & 33 & 7 & 45 & 12 & 33 & 11 & 0.642 \\
\hline Dyspnoea & 9 & 4 & 29 & 12 & 33 & 16 & 0.207 \\
\hline Insomnia & 51 & 8 & 43 & 13 & 33 & 16 & 0.601 \\
\hline Appetite loss & 36 & 11 & 62 & 14 & 40 & 17 & 0.394 \\
\hline Constipation & 11 & 6 & 24 & 11 & 13 & 12 & 0.571 \\
\hline Diarrhoea & 18 & 8 & 14 & 9 & 13 & 7 & 0.948 \\
\hline Financial difficulties & 33 & 11 & 52 & 16 & 20 & 7 & 0.407 \\
\hline Global health status & 65 & 6 & 48 & 8 & 52 & 12 & 0.322 \\
\hline
\end{tabular}

SE: standard error. 
Table 2. QLQ-HN35 scores according to tumor location.

\begin{tabular}{|c|c|c|c|c|c|c|c|}
\hline \multirow{3}{*}{ Scale/item } & \multicolumn{6}{|c|}{ SCC location } & \multirow{3}{*}{$P$} \\
\hline & \multicolumn{2}{|c|}{ Oral $(n=15)$} & \multicolumn{2}{|c|}{ Pharyngeal $(n=7)$} & \multicolumn{2}{|c|}{ Laryngeal $(n=5)$} & \\
\hline & Mean & SE & Mean & SE & Mean & SE & \\
\hline Pain & 43 & 7 & 35 & 12 & 23 & 10 & 0.444 \\
\hline Swallowing & 46 & 9 & 40 & 14 & 38 & 12 & 0.918 \\
\hline Teeth & 44 & 12 & 24 & 13 & 53 & 20 & 0.541 \\
\hline Opening mouth & 33 & 10 & 33 & 16 & 0 & 0 & 0.254 \\
\hline Dry mouth & 40 & 11 & 48 & 15 & 33 & 19 & 0.846 \\
\hline Sticky saliva & 53 & 11 & 57 & 16 & 40 & 17 & 0.785 \\
\hline Senses problems & 52 & 9 & 50 & 13 & 37 & 15 & 0.698 \\
\hline Coughing & 20 & 7 & 38 & 14 & 40 & 15 & 0.462 \\
\hline Speech problems & 36 & 7 & 32 & 12 & 24 & 11 & 0.729 \\
\hline Felt ill & 22 & 9 & 62 & 12 & 33 & 16 & 0.072 \\
\hline Trouble with social contact & 27 & 6 & 30 & 13 & 21 & 7 & 0.862 \\
\hline Trouble with social eating & 39 & 9 & 35 & 12 & 33 & 14 & 0.942 \\
\hline Less sexuality & 41 & 10 & 50 & 11 & 20 & 12 & 0.359 \\
\hline Pain killers & 53 & 13 & 86 & 13 & 80 & 18 & 0.312 \\
\hline Nutritional supplements & 47 & 13 & 71 & 17 & 20 & 18 & 0.203 \\
\hline Feeding tube & 20 & 10 & 43 & 19 & 0 & 0 & 0.201 \\
\hline Weight loss & 67 & 12 & 71 & 17 & 60 & 22 & 0.919 \\
\hline Weight gain & 20 & 10 & 29 & 17 & 60 & 22 & 0.228 \\
\hline
\end{tabular}

SE: standard error.

Table 3. UW-QOL scores according to tumor location.

\begin{tabular}{|c|c|c|c|c|c|c|c|}
\hline \multirow{3}{*}{ Scale/item } & \multicolumn{6}{|c|}{ SCC location } & \multirow{3}{*}{$P$} \\
\hline & \multicolumn{2}{|c|}{ Oral $(n=15)$} & \multicolumn{2}{|c|}{ Pharyngeal $(n=7)$} & \multicolumn{2}{|c|}{ Laryngeal $(n=5)$} & \\
\hline & Mean (SE) & $\%$ best score & Mean (SE) & $\%$ best score & Mean (SE) & $\%$ best score & \\
\hline Pain & $50(8)$ & 13 & $57(11)$ & 29 & $75(7)$ & 20 & 0.267 \\
\hline Appearance & $67(8)$ & 27 & $46(6)$ & 0 & $85(9)$ & 60 & 0.063 \\
\hline Activity & $52(6)$ & 0 & $61(11)$ & 14 & $50(19)$ & 20 & 0.809 \\
\hline Recreation & $57(7)$ & 7 & $46(8)$ & 0 & $50(7)$ & 0 & 0.646 \\
\hline Swallowing & $58(10)$ & 33 & $67(13)$ & 43 & 73 (1 1) & 40 & 0.698 \\
\hline Chewing & $50(9)$ & 27 & 64 (13) & 43 & $50(14)$ & 20 & 0.685 \\
\hline Speech & $71(8)$ & 40 & $71(14)$ & 57 & $67(16)$ & 40 & 0.972 \\
\hline Shoulder function & $84(8)$ & 73 & $90(9)$ & 86 & $100(0)$ & 100 & 0.503 \\
\hline Taste & $51(10)$ & 33 & $38(16)$ & 29 & $60(22)$ & 60 & 0.671 \\
\hline Saliva & $76(7)$ & 53 & $71(14)$ & 57 & $73(15)$ & 60 & 0.962 \\
\hline Mood & $57(8)$ & 20 & $61(15)$ & 43 & $70(13)$ & 40 & 0.754 \\
\hline Anxiety & $51(10)$ & 27 & $72(12)$ & 43 & $57(15)$ & 20 & 0.505 \\
\hline \multicolumn{8}{|l|}{ Global questions } \\
\hline $\begin{array}{l}\text { A. Health-related QOL compared } \\
\text { to month before had cancer }\end{array}$ & $75(9)$ & 80 & $75(5)$ & 100 & $65(15)$ & 80 & 0.828 \\
\hline $\begin{array}{l}\text { B. Health-related QOL during the } \\
\text { past } 7 \text { days }\end{array}$ & $49(6)$ & 47 & $34(8)$ & 29 & $56(4)$ & 80 & 0.243 \\
\hline $\begin{array}{l}\text { C. Overall QOL during the past } \\
7 \text { days }\end{array}$ & $53(6)$ & 53 & $40(6)$ & 29 & $60(11)$ & 80 & 0.287 \\
\hline \multicolumn{8}{|l|}{ Composite scores } \\
\hline Physical function & $75(5)$ & - & $60(6)$ & - & $68(6)$ & - & 0.614 \\
\hline Social function & $58(4)$ & - & $65(5)$ & - & $67(6)$ & - & 0.387 \\
\hline
\end{tabular}

SE: standard error. 
scores were calculated according to the instructions provided in the instrument manuals.

The chi-square test and one-way analyses of variance (ANOVAs) were used to compare QLQ-C30, QLQ-HN35, and UW-QoL scores across tumor location groups. The Statistica software (version 7.0 for Windows; StatSoft, Inc., Tulsa, OK) was used, and the significance level was established as $p<0.05$.

\section{Results}

Patients' sociodemographic and clinical data are presented, and compared between the groups, in Table 4. Age, sex, T stage, and antineoplastic treatment type did not differ according to tumor location, namely oral, pharyngeal, or laryngeal. QLQ-C30, QLQ-HN35, and UW-QoL scores are presented according to tumor location in Tables 1-3. None of the mean scores obtained for the three questionnaires differed significantly among the three tumor location groups.

As reported in Table 1, QLQ-C30 scores did not differ among SCC location groups for any of the scales. Among patients with oral-cavity SCC, the highest average scale score was for social function and the lowest was for dyspnea. Among those with pharyngeal cancer, the highest average scale score was for physical function and the lowest was for diarrhea. Among patients with SCC in the larynx, the highest average scale score was for social function and the lowest was for nausea and vomiting.

As reported in Table 2, the QLQ-HN35 scale with the highest mean score in the oral-cavity cancer group was weight loss and the lowest scores were for coughing, feeding tube, and weight gain. Among patients with pharyngeal cancer, the highest average score was for the painkillers scale and the lowest was for the teeth scale. Among patients with laryngeal cancer, the highest average score was for the painkillers scale and the lowest was for the mouth opening scale.

Among the UW-QOL scales (Table 3), the shoulder function scale had the highest mean score in the all three tumor-location groups. The lowest mean scale scores among patients with oral-cavity cancer were obtained for pain and chewing. The lowest mean scale scores among patients with pharyngeal cancer was taste. Finally, the lowest mean scale scores among patients with laryngeal cancer were obtained for recreation and chewing. Regarding the UW-QOL issue importance question, patients with oral SCC prioritized taste, pain, and chewing; those with pharyngeal SCC prioritized pain, appearance, and taste; and patients with laryngeal SCC tended to rank pain, chewing, and speech as most important (Table 5).

\section{Discussion}

To our knowledge, this work is the first to assess health-related QoL in patients with SCC according to tumor location. In this study, health-related QOL was evaluated using the QLQ-C30, QLQ-HN35, and UW-QOL, as in previous studies. ${ }^{2,3,5,6,6,14,16,17}$ Our QLQ-C30 results are similar to those reported by Crombie $e t$ al. $^{3}$ and Ch'ng et al. ${ }^{16}$ for oral SCC and to those reported by Tribius et al. ${ }^{17}$ for head and neck SCC. The global health status scores obtained in this study are similar to those reported in a previous study of patients with head and neck cancer. ${ }^{17}$

Although questionnaire scores did not differ significantly among the study groups for any of the scales, we observed some trends that could be clinically

Table 4. Sociodemographic and clinical data.

\begin{tabular}{lccccc}
\hline \multirow{2}{*}{ Variable } & Total cohort & \multicolumn{2}{c}{ SCC location } & \multicolumn{2}{c}{ Chi-square } \\
\cline { 2 - 5 } & $(\mathrm{n}=27)$ & Oral $(\mathrm{n}=15)$ & Pharyngeal $(\mathrm{n}=7)$ & Laryngeal $(\mathrm{n}=5)$ & $\mathrm{p}$ \\
\hline Mean age $\pm \mathrm{SD}$, years & $59.89 \pm 9.61$ & $61.07 \pm 10.09$ & $57.43 \pm 4.27$ & $59.80 \pm 11.69$ & 0.3510 \\
Gender, males: females & $21: 06$ & $12: 03$ & $05: 02$ & $04: 01$ & 0.8956 \\
T stage, T1/T2:T3/T4 & $16: 11$ & $07: 08$ & $05: 02$ & $04: 01$ & 0.3128 \\
Antineoplastic treatment* & & & & $01: 02: 05$ & 0.1076 \\
Surgery:radiotherapy:chemotherapy & $04: 13: 21$ & $02: 09: 11$ & $01: 02: 05$ & & \\
\hline
\end{tabular}

SD: standard deviation; *Some patients received more than one type of antineoplastic therapy. 
Table 5. Ranking of patient priorities according to tumor location.

\begin{tabular}{cccc}
\hline Priority rank & \multicolumn{3}{c}{ SCC location } \\
\cline { 2 - 4 } 1 & Oral $(\mathrm{n}=15)$ & Pharyngeal $(\mathrm{n}=7)$ & Laryngeal $(\mathrm{n}=5)$ \\
2 & Taste & Pain & Pain \\
3 & Pain & Appearance & Speech \\
4 & Chewing & Taste & Taste \\
5 & Saliva & Mood & Mood \\
6 & Anxiety & Anxiety & Anxiety \\
7 & Mood & Activity & Saliva \\
8 & Swallowing & Chewing & Appearance \\
9 & Appearance & Speech & Activity \\
10 & Activity & Saliva & Recreation \\
11 & Recreation & Recreation & Swallowing \\
12 & Shoulder function & Swallowing & Shoulder function \\
\hline
\end{tabular}

relevant. Notably, the mean QLQ-HN35 dyspnea score was 20 or more points worse in the oral-cavity SCC group than in the other two groups. The mean role and social function scores were more than 10 points worse in the pharyngeal SCC group than in the other groups, and the mean financial difficulties score was more than 10 points worse in the laryngeal cancer group than in the other two groups.

OurQLQ-HN35 results were similar to those reported by Tribius et al. ${ }^{17}$ for head and neck SCC. Relative to the other two tumor-location groups' mean QLQ-HN35 scores, the mean QLQ-HN35 scale scores obtained for the oral-cavity cancer group were 20 points worse for painkillers and 10 points worse for coughing and feeling ill. Meanwhile, the pharyngeal cancer group's mean teeth score was more than 20 points worse than the scores of the other two groups; and the laryngeal cancer group's mean scores for mouth opening, nutritional supplements, and feeding tube were more than 20 points worse than those of the other two groups.

Our finding that the shoulder function scale score was the highest UW-QOL scale score for all three tumor-location groups (oral cavity, pharynx, and larynx) corroborates the results of Andrade et al. ${ }^{2}$ and
Crombie et al. ${ }^{3}$ Notably, the UW-QOL appearance score was more than 20 points worse in the pharyngeal SCC group than in the other groups. The UW-QOL data show that pain was one of the most important problems experienced by these patients in the previous 7 days. This finding, similar to that reported by Andrade et al., ${ }^{2}$ reflects the importance of patient monitoring in all phases of treatment and rehabilitation.

This study had several limitations. First, the sample was small, reflecting the number of patients with SCC undergoing treatment at the Cancer Hospital of Londrina. Second, previous studies have suggested that variables such as age, sex, T stage, and antineoplastic treatment type can influence health-related QOL analysis. ${ }^{2,78}$ However, the homogeneity of the present sample in terms of these variables and the treatment of all of the patients in the same hospital strengthen the validity of the comparisons made in this study.

\section{Conclusion}

Based on the results of this study, it can be concluded that the health-related QOL of patients with SCC was not influenced by tumor location.

\section{References}

1. Hammerlid E, Bjordal K, Ahlner-Elmqvist M, Jannert M, Kaasa S, Sullivan $M$ et al. Prospective longitudinal quality of life study of patients with head and neck cancer a feasibility study including the EORTC QLQ-C30.

Otolaryngol Head Neck Surg. 1997;116(6):666-73. https://doi.org/10.1016/S0194-5998(97)70246-8

2. Andrade F, Antunes J, Durazzo M. Evaluation of the quality of life of patients with oral cancer in Brazil. Braz Oral Res. 2006;20(4):290-6. https://doi.org/10.1590/S1806-83242006000400002 
Health-related quality of life of patients with squamous cell carcinoma: a comparison according to tumor location

3. Crombie AK, Farah CS, Batstone MD. Health-related quality of life of patients treated with primary chemoradiotherapy for oral cavity squamous cell carcinoma: a comparison with surgery. Br J Oral Maxillofac Surg. 2014;52(2):111-7. https://doi.org/10.1016/i.bjoms.2013.09.014

4. Haes J, Curran D, Young T, Bottomley A, Flechtner H, Aaronson $\mathrm{N}$ et al. Quality of life evaluation in oncological clinical trials: the EORTC model. Eur J Cancer. 2000;36(7):821-5. https://doi.org/10.1016/S0959-8049(00)00007-1

5. Rogers SN, Laher SH, Overend L, Lowe D. Importancerating using the University of Washington quality of life questionnaire in patients treated by primary surgery for oral and oro-pharyngeal cancer. J Craniomaxillofac Surg. 2002;30(2):125-32. https://doi.org/10.1054/jcms.2001.0273

6. Ryzek DF, Mantsopoulos K, Künzel J, Grundtner P, Zenk J, Iro $\mathrm{H}$ et al. Early stage oropharyngeal carcinomas: comparing quality of life for different treatment modalities. BioMed Research International. 2014;2014:421964. https://doi.org/10.1155/2014/421964

7. Vartanian JG, Carvalho AL, Yueh B, Priante AV, Melo RL, Correia $\mathrm{LM}$ et al. Long-term quality-of-life evaluation after head and neck cancer treatment in a developing country. Arch Otolaryngol Head Neck Surg. 2004;130(10):1209-13. https://doi.org/10.1001/archotol.130.10.1209

8. Rogers SN, O'donnell JP, Williams-Hewitt S, Christensen JC, Lowe D. Health-related quality of life measured by the UW-QOL: reference values from a general dental practice. Oral Oncol. 2006;42(3):281-7. https://doi.org/10.1016/i.oraloncology.2005.08.002

9. Kowalski LP, Franco EL, Torloni H, Fava AS, Andrade Sobrinho J, Ramos G. Latenes of diagnosis of oral and oropharyngeal carcinoma: factors related to the tumour, the patient and health professionals. Eur J Cancer B Oral Oncol. 1994;30B(3):167-73. https://doi.org/10.1016/0964-1955(94)90086-8
10. Morton RP, Izzard ME. Quality-of-life outcomes in head and neck cancer patients. World J Surg. 2003;27(7):884-9. https://doi.org/10.1007/s00268-003-7117-2

11. Specht L. Oral complications in the head and neck radiation patient: introduction and scope of the problem. Support Care Cancer. 2002;10(1):36-9. https://doi.org/10.1007/s005200100283

12. Vissink A, Burlage FR, Spijkervet FK, Jansma J, Coppes RP. Prevention and treatment of the consequences oh head and neck radiotherapy. Crit Rev Oral Biol Med. 2003;14(3):213-25. https://doi.org/10.1177/154411130301400306

13. Sayed SI, Elmiyeh B, Rhys-Evans P, Syrigos KN, Nutting CM, Harrington KJ et al. Quality of life and outcomes research in head and neck cancer: a review of the state of the discipline and likely future directions. Cancer Treat Rev. 2009;35(5):397-402. https://doi.org/10.1016/i.ctrv.2009.03.001

14. Tschiesner U, Schuster L, Strieth S, Harréus U. Functional outcome in patients with advanced head and neck cancer: surgery and reconstruction with free flaps versus primary radiochemotherapy. Eur Arch Otorhinolaryngol. 2012;269(2):629-38. https://doi.org/10.1007/s00405-011-1642-7

15. Movsas B. Quality of life in oncology trials: a clinical guide. Semin Radiat Oncol. 2003;13(3):235-47. https://doi.org/10.1016/S1053-4296(03)00029-8

16. Ch'ng S, Oates J, Gao K, Foo K, Davies S, Brunner M et al. Prospective quality of life assessment between treatment groups for oral cavity squamous cell carcinoma. Head Neck. 2014;36(6):834-40. https://doi.org/10.1002/hed.23387

17. Tribius S, Reemts E, Prosch C, Raguse M, Petersen C, Kruell $A$ et al. Global quality of life during the acute toxicity phase of multimodality treatment for patients with head and neck cancer: can we identify patients most at risk of profound quality of life decline? Oral Oncol. 2012;48(9):898-904. https://doi.org/10.1016/j.oraloncology.2012.03.011 


\section{Health-related quality of life of} patients with squamous cell carcinoma:

a comparison according to tumor location. Braz Oral Res. 2017;31:e105.

Where is read:

(a)Universidade Estadual do Norte do Paraná - Unopar, Londrina, PR, Brazil.

It should read:

(a)Universidade Norte do Paraná - Unopar, Londrina, PR, Brazil.

DOI: 10.1590/1807-3107BOR-2017.vol31.0105erratum 